\title{
ORGANIZATIONAL AND ECONOMIC BASES OF ENERGY CONSERVATION IN AGRICULTURE
}

\author{
ОРГАНИЗАЦИОННО-ЭКОНОМИЧЕСКИЕ ОСНОВЫ ЭНЕРГОСБЕРЕЖЕНИЯ \\ В СЕЛЬСКОМ ХОЗЯЙСТВЕ
}

\author{
N. Lisjutchenko, General Manager ${ }^{1}$
}

Н.Н. Лисютченко, генеральный директор

\author{
A. Polukhin, Cand.Econ.Sci. ${ }^{2}$ \\ А.А. Полухин, кандидат экономических наук
}

${ }^{1}$ Open Joint-Stock Company «Oryol social bank», Orel City, Russia

Открытое акционерное общество «Орловский социальный банк», г. Орёл, Россия +7 (4862) 54-16-01, E-mail: info@socbank.ru

${ }^{2}$ All-Russia Scientific Research Institute of Rural Economics, Moscow, Russia

ВНИИ экономики сельского хозяйства, г. Москва, Россия +7 (4862) 45-40-64, E-mail: polukhinogac@yandex.ru

Received March 27, 2012

\begin{abstract}
АННОТАЦИЯ
Аграрное производство России на современном этапе является весьма энергоёмким. В себестоимости производства сельскохозяйственной продукиии общая стоимость топливно-энергетических ресурсов постоянно растет: в 2000 г. было 36,5 млрд. руб., 2008 г. 92 млрд. руб., 2009 г. - 110,6 млрд. руб., а в 2010 г. возросла до 119,8 млрд. руб. или выросла в 3,3 раза. Проведенный анализ потребления сельскохозяйственными предприятиями основных энергетических ресурсов за период с 1990 по 2010 год показал уменьшение общих и удельных объемов потребления дизельного топлива, бензина и электроэнергии в 5-7 раз. Снижение расхода энергоресурсов объясняется как вынужденная экономия ресурсов из-за недостатка средств для их приобретения, так и внедрением сельскохозяйственньми предприятиями энерго- и ресурсосберегающих мероприятий (применение ресурсосберегающих технологий при производстве продукции, использование газомоторного топлива, биотоплива и альтернативных источников энергии). Для решения данной проблемы государству совместно с бизнесом в приоритетном порядке необходимо будет построить эффективную систему инновационного развития сельского хозяйства, стимулировать участие аграрной науки и образовательной системы в этом процессе, модернизировать отечественное сельхозмашиностроение и инженерно-технологическую инфраструктуру.
\end{abstract}

\begin{abstract}
Russian agricultural production at current stage is very energy intensive. At the cost of agricultural production overall cost of energy resources is growing: in 2000 was 36.5 billion rubles, 2008 - 92 billion rubles, 2009 - 110.6 billion rubles, and in 2010 rose to 119.8 billion rubles, or increased by 3.3 times. The analysis of consumption of the main energy sources for the period from 1990 to 2010 showed a decrease in general and the specific consumption of diesel fuel, gasoline and electricity by 5-7 times. Reducing energy consumption is explained as a forced saving resources because of lack of funds for the acquisition and implementation of agricultural enterprises of energy and resource saving measures (resource-saving technologies in the production process, motor fuel, biofuels and alternative energy sources). To solve this problem State and business in a matter of priority should be to build an effective system of innovation development for agriculture, promote the participation of agricultural science and education system in this process, modernize the domestic agricultural machinery, engineering and technology infrastructure.
\end{abstract}


N. LISJUTCHENKO, Open Joint-Stock Company «Oryol social bank»

A. POLUKHIN, All-Russia Scientific Research Institute of Rural Economics

\section{КЛЮЧЕВЫЕ СЛОВА}

Сельское хозяйство; Энергосбережение; Экономическая оценка; Реализаџия потенциала; Ресурсньй потенциал.

\section{KEY WORDS}

Agriculture; Energy saving; Economic evaluation; Implementation capacity; Resource potential.

Энергосбережение представляет собой процесс эффективного использования материально-технических, топливноэнергетических, финансовых и других ресурсов. Цель энергосбережения - производство сельскохозяйственной продукции с лучшими качественными показателями при минимуме совокупных затрат энергетических ресурсов и повышение экономической отдачи. Проблема организационноэкономического механизма энергосбережения в последние годы стало особенно актуальной. Дмитрий Медведев в своем послании к Федеральному собранию в 2010 году четко обозначил цель: «Повысить к 2020 году энергоэффективность экономики на $40 \% »$.

Аграрное производство России на современном этапе является весьма энергоёмким. В себестоимости производства сельскохозяйственной продукции общая стоимость топливно-энергетических ресурсов постоянно растет: в 2000 г. было 36,5 млрд. руб., 2008 г. - 92 млрд. руб., 2009 г. - 110,6 млрд. руб., а в 2010 г. возросла до 119,8 млрд. руб. или выросла в 3,3 раза. Но в физическом выражении происходит уменьшение их потребления. Их общий удельный вес постоянно снижался: в 2010 г. достиг 9,9\%, в том числе нефтепродукты - 5,9\%, электроэнергия - $2,8 \%$ и топливо $-1,2 \%$ (для сравнения в 2009 г. общая доля затрат на энергетические ресурсы в структуре затрат $10,4 \%$, в том числе нефтепродукты - 6,5\%, электроэнергия $-2,8 \%$ и топливо $-1,1 \%)^{1}$.

Следует указать, что энергосбережение не сводится только к экономии топлива и электричества, ключевыми направлениями энергосбережения также являются снижение потребности в энергетических мощностях (техники и оборудования), снижение энерго-

\footnotetext{
${ }^{1}$ Сводный годовой отчет сельскохозяйственных предприятий РФ, 2010 г.
}

ёмкости производства в целом, использование в производстве альтернативных источников энергии.

Организационно-экономический механизм энергосбережения сельскохозяйственных предприятий обусловлен дефицитом энергетических ресурсов и ростом цен на горючесмазочные материалы и топливо. Неэффективное использование технических и энергетических ресурсов становится одним из ключевых фактором снижения конкурентоспособности сельскохозяйственной продукции. Нерациональное уменьшение потребления энергоресурсов, что приводит к невыполнению отдельных технологических операций, увеличению сроков выполнения механизированных работ и соответственно к снижению урожайности культур и продуктивности скота, а также качества продукции.

Значение энергосбережения в сельскохозяйственном производстве наглядно видно при анализе структуры расходов предприятий. Отметим, что в разрезе отраслей сельского хозяйства потребность в энергетических ресурсах значительно разнится, так в растениеводстве основные затраты на энергоресурсы формируются за счет горючесмазочных материалов, в животноводстве затраты на электроэнергию.

Поэтому для рационального потребления энергетических ресурсов и соответственно снижения себестоимости производства продукции, экономическая деятельность сельскохозяйственных предприятий должна быть направлена на внедрение технических, технологических и организационных мероприятий.

В соответствии с Федеральным законом «Об энергосбережении» под энергосбережением понимается реализация правовых, организационных и экономических мер, направленных на эффективное использование энергетических ресурсов и вовлечение в хозяйственный оборот возобновляемых источников энергии; под энергосберегающей по- 
литикой государства - это правовое, организационное и финансово-экономическое регулирование деятельности в области энергосбережения.

Экономический механизм энергосбережения формируется на основе основных направлений снижения энергоемкости продукции: технические, технологические, организационные, которые они мало внедряются на практике. Успешной реализации этих резервов будет способствовать:

- определение показателей и анализ энергопотребления и энергосбережения;

- технико-экономическое обоснование технологических и технических мероприятий по энергосбережению в том числе производства и применения альтернативных видов топлива;

- разработка форм и методов государственной поддержки энергосбережения на федеральном и региональном уровне;
- разработка рекомендаций по экономическому механизму энергосбережения в сельскохозяйственных предприятиях;

- экономические взаимоотношения с поставщиками энергоресурсов;

- разработка нормативов энергопотребления и энергоэффективности.

Показателем состояния материальнотехнической базы является обеспеченность основными элементами на 1000 га пашни или площади посева соответствующих культур. В табл. 1 представлены данные об обеспеченности посевных площадей техникой.

Из табл. 1 видно, что сокращение количества комбайнов связано с такими факторами, как дороговизна техники и диспаритет цен, изменение технических характеристик (рост производительности), технологии возделывания отдельных культур и изменение площади посевов сельскохозяйственных культур.

Таблица 1 - Обеспеченность сельскохозяйственных организаций России сельхозтехникой 2

\begin{tabular}{|c|c|c|c|c|c|c|c|}
\hline \multirow{2}{*}{ Показатели } & \multicolumn{6}{|c|}{ Годы } & \multirow{2}{*}{$\begin{array}{c}2010 \text { г., \% } \\
\kappa 2009 \text { г. }\end{array}$} \\
\hline & 2005 & 2006 & 2007 & 2008 & 2009 & 2010 & \\
\hline \multicolumn{8}{|c|}{ на 1000 га посевов (посадки) соответствующих культур приходится комбайнов, шт. } \\
\hline Зерноуборочных & 3,9 & 3,7 & 3,4 & 3,2 & 2,9 & 3,0 & 105,3 \\
\hline картофелеуборочных & 32,3 & 28,1 & 25,2 & 23,3 & 18,2 & 16,0 & 88,0 \\
\hline льноуборочных & 21,6 & 21,0 & 21,4 & 18,6 & 17,8 & 24,0 & 134,7 \\
\hline свеклоуборочных машин & 10,8 & 7,6 & 6,1 & 6,4 & 5,4 & 4,0 & 66,1 \\
\hline Приходится тракторов на 1000 га пашни, шт. & 6,0 & 5,0 & 5,0 & 5,0 & 4,0 & 4,2 & 95,9 \\
\hline \multicolumn{8}{|c|}{ приходится посевов (посадки) соответствующих культур на единицу техники, га } \\
\hline Зерноуборочный & 253 & 270 & 291 & 317 & 344 & 327 & 95 \\
\hline картофелеуборочный & 31 & 36 & 40 & 43 & 55 & 62 & 114 \\
\hline льноуборочный & 46 & 48 & 47 & 54 & 56 & 42 & 74 \\
\hline на одну свеклоуборочную машину & 93 & 131 & 165 & 156 & 184 & 278 & 151,2 \\
\hline Нагрузка пашни на один трактор, га & 181 & 187 & 197 & 210 & 226 & 236 & 104 \\
\hline $\begin{array}{l}\text { Энергообеспеченность (приходится энергетиче- } \\
\text { ских мощностей на } 100 \text { га посевной площади), л.с. }\end{array}$ & 270 & 254 & 243 & 234 & 227 & 227 & 100,0 \\
\hline
\end{tabular}

Таблица 2 - Наличие энергетических мощностей, млн. л.с.

\begin{tabular}{|c|c|c|c|c|c|c|c|}
\hline п/п & 2005 & 2006 & 2007 & 2008 & 2009 & 2010 & $\begin{array}{l}2010 \text { в \% } \\
\text { к } 2009\end{array}$ \\
\hline $\begin{array}{l}\text { Суммарная номинальная мощность двигателей } \\
\text { тракторов }\end{array}$ & 52,6 & 49,0 & 46,2 & 42,6 & 39,2 & 37,3 & 95,2 \\
\hline $\begin{array}{l}\text { Суммарная номинальная мощность двигателей } \\
\text { комбайнов и самоходных машин }\end{array}$ & 27,1 & 25,1 & 23,4 & 22,1 & 20,5 & 19,7 & 96,2 \\
\hline $\begin{array}{l}\text { Суммарная номинальная мощность двигателей } \\
\text { автомобилей }\end{array}$ & 47,8 & 43,4 & 40,0 & 36,2 & 33,8 & 32,3 & 95,4 \\
\hline $\begin{array}{l}\text { Суммарная номинальная мощность прочих } \\
\text { механических двигателей }\end{array}$ & 1,9 & 1,6 & 1,5 & 1,5 & 1,4 & 1,2 & 86,8 \\
\hline $\begin{array}{l}\text { Суммарная номинальная мощность электро- } \\
\text { двигателей и электроустановок }\end{array}$ & 27,3 & 25,0 & 23,0 & 20,4 & 19,9 & 19,0 & 95,6 \\
\hline $\begin{array}{l}\text { Рабочий скот в пересчете на механическую } \\
\text { силу }\end{array}$ & 0,2 & 0,2 & 0,1 & 0,1 & 0,1 & 0,1 & 100,3 \\
\hline Всего энергетических мощностей & 156,9 & $14 \overline{4}, 2$ & 134,2 & 123,0 & 114,9 & 109,6 & 95,4 \\
\hline
\end{tabular}

\footnotetext{
${ }^{2} \mathrm{http}: / / \mathrm{gks} . \mathrm{ru}$
} 
N. LISJUTCHENKO, Open Joint-Stock Company «Oryol social bank»

A. POLUKHIN, All-Russia Scientific Research Institute of Rural Economics

Обращает на себя внимание тот факт, что в количественном выражении зерноуборочных комбайнов стало меньше на $38 \%$, а в расчете на единицу площади посевов зерновых культур их количество сократилось уже на $23 \%$.

Развитие сельского хозяйства напрямую влияет на удельный расход энергоресурсов. Они имеют такую же тенденцию изменения, что и общий расход энергоресурсов: значительное уменьшение с 1990 по 2000 г. и дальнейшей стабилизации их расхода в 2001-2010 гг.

По данным Института энергетической стратегии Российской Федерации, российский агропромышленный комплекс потребляет в настоящее время около 70 млн. т условного топлива в год из 1600 млн. т в целом по стране. В сельском хозяйстве России используются основные энергоресурсы (автобензин, дизельное топливо, топочный мазут, дизельное масло, электроэнергия, природный газ), биотопливо и возобновляемые источники энергии. Расход основных видов энергоресурсов в натуральном выражении показан в таблице 3. Их максимальная величина была в 1990 г. и за последующие двадцать лет она значительно уменьшилась.

Основным видом энергоресурсов, потребляемым в сельском хозяйстве, является дизельное топливо. В 1990 г. его было потреблено 20 млн. т, и в 2005 г. расход снизился до 4,4 млн. т или в 4,5 раза. В последующие годы снижение расхода было незначительное, и в 2010 г. расход дизельного топлива составил 3,8 млн. т или на 13,6 \% меньше по сравнению с 2005 г. Расход бензина снизился с 11,3 млн. т в 1990 г. до 1,6 млн. т в 2005 г. или в 7,1 раза. В последующие годы он изменялся незначительно, и в 2010 г. составил 0,9 млн. т или на $44 \%$ меньше по сравнению с 2005 г.

Таблица 3 - Использование энергии в сельском хозяйстве России

\begin{tabular}{|c|c|c|c|c|c|c|c|}
\hline Вид энергии & 1990 & 1995 & 2000 & 2005 & 2008 & 2009 & 2010 \\
\hline Автобензин, млн. т & 11,3 & 3,0 & 1,8 & 1,6 & 1,3 & 1,1 & 0,9 \\
\hline Дизельное топливо, млн. т & 20,0 & 6,7 & 5,0 & 4,4 & 4,3 & 4,1 & 3,8 \\
\hline Электроэнергия, млрд. кВт.ч & 67,3 & 53,0 & 30,2 & 16,9 & 14,3 & 13,5 & 13,0 \\
\hline
\end{tabular}

Потребление бензина в 1990 г. было в 1,8 раза меньше расхода дизельного топлива, в 2005 г. - в 2,8 раза меньше и 2010 г. - в 4,2 раза меньше. Это говорит о значительном сокращении объемов работ, выполняемых автомобилями с бензиновыми двигателями.

Расход электроэнергии на производственные нужды в 1990 г. составлял 67,3 млрд. кВт.ч, и в 2005 г. снизился до 16,9 млрд. кВт.ч или в 4 раза. Её потребление в последующие годы постоянно уменьшалось и в 2009 г. достигло 13,5 млрд. кВт.ч или в 1,3 раза меньше по сравнению с 2005 г.

В последующие годы его потребление стабилизировалось, и в 2010 г. удельный расход дизельного топлива достиг величины 67,8 кг/га или на $0,6 \%$ больше по сравнению c 2000 г. Удельный расход бензина на 1 га посевной площади снизился с 98 кг в 1990 г. до 16 кг в 2010 г. или в 6,1 раза. Минимальный расход приходится на 2010 год. Удельный расход электроэнергии на производственные нужды на 1 га посевной площади в 1990 г. составлял 584 кВт.ч и снизился в 2000 г. до 407 кВт.ч или в 1,4 раза; в 2009 г. до 230 кВт.ч или в 2,5 раза.

Общий расход нефтепродуктов (дизельное топливо, бензин, масла) в стоимостном выражении до 2008 г. постоянно возрастал: в 2000 г. он составлял 36,5 млрд. руб. и в 2008 г. вырос до 92 млрд. руб. или в 2,5 раза. И только в 2010 г. он снизился до уровня 70,9 млрд. руб. или в 1,3 раза по сравнению с 2008 г. (табл. 4).

Таблица 4 - Расход ресурсов в сельскохозяйственных организациях России, млрд. руб. (по данным годовых отчетов Минсельхоза РФ)

\begin{tabular}{|c|c|c|c|c|c|c|c|c|c|c|c|}
\hline$\Pi / \Pi$ & 2000 & 2001 & 2002 & 2003 & 2004 & 2005 & 2006 & 2007 & 2008 & 2009 & 2010 \\
\hline \multicolumn{12}{|c|}{ Сельскохозяйственные организации - всего } \\
\hline Нефтепродукты & 36,5 & 41,1 & 37,4 & 41,5 & 52,0 & 61,3 & 67,3 & 67,7 & 92,0 & 71,3 & 70,9 \\
\hline Электроэнергия & 7,6 & 7,8 & 11,3 & 13,6 & 15,4 & 17,0 & 18,8 & 21,0 & 25,0 & 30,0 & 34,8 \\
\hline Топливо & 3,6 & 4,6 & 4,7 & 5,7 & 6,5 & 7,7 & 8,8 & 9,7 & 10,7 & 12,1 & 14,4 \\
\hline \multicolumn{11}{|c|}{ в том числе растениеводство } & \\
\hline Нефтепродукты & 24,9 & 28,4 & 25,6 & 28,0 & 36,0 & 43,0 & 47,8 & 48,6 & 67,7 & 52,5 & 50,7 \\
\hline Электроэнергия & 2,1 & 2,2 & 2,8 & 3,3 & 3,9 & 4,2 & 4,5 & 5,2 & 6,0 & 7,2 & 7,6 \\
\hline Топливо & 1,4 & 1,8 & 1,9 & 2,3 & 2,8 & 3,5 & 4,1 & 4,7 & 4,3 & 4,8 & 5,5 \\
\hline
\end{tabular}


Стоимость потребленной электроэнергии в 2000 г. составляла 7,6 млрд. руб., и выросла в 2010 г. до 34,8 млрд. рублей или в 4 раза (табл. 2). Но за этот период расход электроэнергии в кВт.ч снизился в 2,2 раза. То есть рост цен составил за этот период в девять раз. Удельный расход нефтепродуктов на 1 гектар сельскохозяйственных угодий в 2000 г. составлял 258 руб. и вырос в 2010 г. до 796 руб. или в 3 раза; на 1 га пашни - с 399 до 1096 руб. или в 2,7 раза (табл. 5).

Удельный расход электроэнергии за этот период вырос на 1 гектар сельскохозяйственных угодий с 54 до 391 руб. или в
6 раз, пашни - с 83 до 540 руб. или в 5,5 раза. Более точно отражает удельный расход топлива показатель в расчете на 1 гектар посевной площади, так как именно для выполнения механизированных работ по возделыванию и уборки сельскохозяйственных культур используется дизельное топливо, бензин, электроэнергия. Размер посевной площади показывает уровень использования пахотных земель в сельскохозяйственных предприятиях, который в 1990 г. составлял $89 \%$, в 1995 г. - 82 \%, в 2000 г. $-73 \%$ и в 2010 г. $-72,6 \%$, т.е. в течение этого периода увеличивался удельный вес неиспользуемой пашни.

Таблица 5 - Расход энергоресурсов на 1 га сельскохозяйственных угодий и пашни в сельскохозяйственных организациях России, руб. (по данным годовых отчетов Минсельхоза РФ)

\begin{tabular}{|c|c|c|c|c|c|c|c|c|c|c|c|}
\hline$\Pi / \Pi$ & 2000 & 2001 & 2002 & 2003 & 2004 & 2005 & 2006 & 2007 & 2008 & 2009 & 2010 \\
\hline \multicolumn{12}{|c|}{ Нефтепродукты: } \\
\hline $\begin{array}{l}\text { на } 1 \text { га } \\
\text { сельхозугодий }\end{array}$ & 258,2 & 290,8 & 264,9 & 321,4 & 443,2 & 520,4 & 659,8 & 701,7 & 987,1 & 775,5 & 796,1 \\
\hline на 1 га пашни & 399,0 & 458,1 & 425,2 & 494,9 & 673,1 & 838,6 & 972,0 & 1016,9 & 1401,8 & 1090,6 & 1095,9 \\
\hline \multicolumn{12}{|c|}{ Электроэнергия: } \\
\hline $\begin{array}{l}\text { на } 1 \text { га } \\
\text { сельхозугодий }\end{array}$ & 54,0 & 55,1 & 80,4 & 105,0 & 131,2 & 144,3 & 184,0 & 217,5 & 268,0 & 326,5 & 390,8 \\
\hline на 1 га пашни & 83,4 & 86,7 & 129,0 & 161,7 & 199,2 & 232,6 & 271,0 & 315,2 & 380,6 & 459,1 & 537,9 \\
\hline \multicolumn{12}{|c|}{ Топливо: } \\
\hline $\begin{array}{l}\text { на } 1 \text { га } \\
\text { сельхозугодий }\end{array}$ & 25,2 & 32,7 & 33,6 & 43,9 & 55,1 & 65,4 & 85,8 & 100,2 & 114,8 & 131,8 & 161,7 \\
\hline на 1 га пашни & 39,0 & 51,4 & 53,9 & 67,5 & 83,7 & 105,3 & 126,4 & 145,3 & 163,0 & 185,4 & 222,6 \\
\hline
\end{tabular}

Удельный вес расходов на приобретение энергоресурсов (горюче-смазочных материалов, электроэнергии и топлива) в 2010 г. составил в затратах на основное производство продукции сельского хозяйства $11 \%$, что больше по сравнению с 1990 г. в 2,4 раза (табл. 6). Для растениеводства он составил соответственно 14,9\% или в 2,8 раза больше и животноводства - 6,9\% или в 2,5 раза больше. Но это обусловлено, в основном, значительным сокращением объемов приобретения минеральных удобрений, техники, комбикормов, строительных материалов.

Таблица 6 - Энергоресурсы в затратах на основное производство продукции сельского хозяйства, $\%$ от всех затрат по годам

\begin{tabular}{|c|c|c|c|c|c|c|c|c|c|}
\hline$\Pi / \Pi$ & 1990 & 1995 & 2000 & 2005 & 2006 & 2007 & 2008 & 2009 & 2010 \\
\hline \multicolumn{10}{|c|}{ Всего на основное производство } \\
\hline Нефтепродукты & 2,7 & 8,4 & 12,0 & 10,7 & 10,3 & 8,6 & 8,9 & 6,5 & 5,9 \\
\hline Электроэнергия & 1,0 & 3,8 & 2,5 & 3,0 & 2,9 & 2,7 & 2,4 & 2,8 & 2,9 \\
\hline Топливо & 0,7 & 1,7 & 1,2 & 1,3 & 1,3 & 1,2 & 1,0 & 1,1 & 1,2 \\
\hline \multicolumn{10}{|c|}{ Растениеводство } \\
\hline Нефтепродукты & 4,3 & 15,3 & 20,4 & 18,3 & 18,0 & 15,1 & 15,3 & 12,1 & 12,1 \\
\hline Электроэнергия & 0,7 & 2,8 & 1,8 & 1,8 & 1,7 & 1,6 & 1,4 & 1,7 & 1,7 \\
\hline Топливо & 0,4 & 1,8 & 1,8 & 1,5 & 1,6 & 1,5 & 1,0 & 1,1 & 1,1 \\
\hline \multicolumn{10}{|c|}{ Животноводство } \\
\hline Нефтепродукты & 1,1 & 3,8 & 5,1 & 4,5 & 4,4 & 3,5 & 3,3 & 2,5 & 2,5 \\
\hline Электроэнергия & 1,1 & 4,3 & 2,9 & 3,8 & 3,7 & 3,4 & 3,1 & 3,4 & 3,4 \\
\hline Топливо & 0,6 & 1,5 & 1,0 & 1,1 & 1,1 & 1,0 & 1,0 & 1,0 & 1,0 \\
\hline
\end{tabular}


N. LISJUTCHENKO, Open Joint-Stock Company «Oryol social bank»

A. POLUKHIN, All-Russia Scientific Research Institute of Rural Economics

Проведенный анализ потребления сельскохозяйственными предприятиями основных энергетических ресурсов за период с 1990 по 2010 год показал уменьшение общих и удельных объемов потребления дизельного топлива, бензина и электроэнергии в 5-7 раз. Снижение расхода энергоресурсов объясняется как вынужденная экономия ресурсов из-за недостатка средств для их приобретения, так и внедрением сельскохозяйственными предприятиями энергоресурсосберегающих мероприятий (применение ресурсосберегающих технологий при производстве продукции, использование газомоторного топлива, биотоплива и альтернативных источников энергии).

К основным элементам экономического механизма технической модернизации относятся:

1. Научное обеспечение энергосбережения в сельском хозяйстве: проведение анализа и совершенствование показателей наличия и использования основных элементов материально-технической базы, обоснование инвестиционной политики и установление источников финансирования собственных и привлеченных, совершенствование методов экономической оценки технологий и техники, инвестиционных проектов, научное обоснование и планирование оптимальной потребности в технике, совершенствование бухгалтерской и статистической отчетности, обоснование технико-экономических нормативов обеспеченности техническими ресурсами. Необходимо восстановить систему разработки и доведения до сельскохозяйственных товаропроизводителей нормативно-научнотехнической информации.

2. Проведение протекционистской политики на рынке сельскохозяйственной техники:

- субсидирование процентных ставок по банковскому кредиту на приобретение техники и инвестиционных кредитов (предлагается субсидировать кредитную ставку в размере ставки рефинансирования). Это связано с тем, что снижение ставки рефинансирования значительно снизило уровень поддержки и снизило конкурентоспособность отечественной техники;
- при поставке техники российского производства сельскохозяйственному товаропроизводителю необходимо предоставлять отсрочку по оплате $50 \%$ стоимости техники до 6 месяцев. Цель кредита приобретение техники и/или оборудования, срок кредита - 5-10 лет; льготный период (уплата только процентов) до 12 месяцев.

- выделение финансирования на разработку и внедрение новых технологий и техники (целевое финансирование разработки новой техники и технологии на конкурсной основе).

3. Субсидирование долгосрочных инвестиционных кредитов для технической модернизации (предлагается субсидировать кредитную ставку в размере ставки рефинансирования):

- субсидирование строительства и ре ᄀконструкции объектов производственной инфраструктуры;

- субсидирование строительства и ре ᄀконструкции мелиоративных систем.

Необходимо создать комфортные условия по кредитованию сельскохозяйственных товаропроизводителей. В настоящее время высокая стоимость и сложная процедура получения кредитов: стоимость залогового имущества в 1,5-2 раза превышает сумму кредита, для финансирования инвестиционного проекта банк требует до $40 \%$ собственных средств заемщика. Вследствие снижения ставки рефинансирования повышается финансовая нагрузка на сельскохозяйственных товаропроизводителей по обслуживанию кредитов. Ориентация бюджетной поддержки на внедрение эффективных технологий, высокопроизводительной техники. В настоящее время субсидируется преимущественно отечественная техника и оборудование, что не стимулирует приобретение высокопроизводительной импортной техники. Выплата субсидий по инвестиционным кредитам должна производиться на конкурсной основе и предусматривать финансовую ответственность бюджетополучателя за достижение запланированных показателей.

4. Снижение затрат на энергоносители в сельском хозяйстве посредством возмещения части затрат на приобретение топлива и смазочных материалов, электриче- 
ской и тепловой энергии. Возмещение $10 \%$ стоимости энергоресурсов снизит на $1,5 \%$ материальные затраты в сельском хозяйстве.

Таким образом, государству совместно с бизнесом в приоритетном порядке необходимо будет построить эффективную систему инновационного развития сельского хозяйства, стимулировать участие аграрной науки и образовательной системы в этом процессе, модернизировать отечественное сельхозмашиностроение и инженерно-технологическую инфраструктуру.

\section{БИБЛИОГРАФИЯ}

Драгайцев В. И. Методика экономической оценки технологий и машин в сельском хозяйстве / В. И. Драгайцев, Н. М. Морозов, А. А. Полухин и др. М.; Россельхозакадемия, 2010. $-148 \mathrm{c}$.

Полухин А.А., Ставцев А.Н. Формирование технической базы для освоения ресурсосберегающих технологий в зернопроизводстве // Вестник ОрёлГАУ. 2008. №6. С. 23-26.
Нормативы потребности АПК в технике для растениеводства и животноводства: нормативы. М.: ФГНУ «Росинформагротех», 2003. - 84 с.

Орловская область в цифрах: сельское хозяйство [Электронный ресурс]. Режим доступа: http://orel.gks.ru. 